\title{
Loss models for long Josephson junctions
}

\section{Olsen, O. H.; Samuelsen, Mogens Rugholm}

\section{Published in:}

Physical Review B

Link to article, DOI:

10.1103/PhysRevB.29.2803

Publication date:

1984

\section{Document Version}

Publisher's PDF, also known as Version of record

Link back to DTU Orbit

Citation (APA):

Olsen, O. H., \& Samuelsen, M. R. (1984). Loss models for long Josephson junctions. Physical Review B, 29(5), 2803-2804. https://doi.org/10.1103/PhysRevB.29.2803

\section{General rights}

Copyright and moral rights for the publications made accessible in the public portal are retained by the authors and/or other copyright owners and it is a condition of accessing publications that users recognise and abide by the legal requirements associated with these rights.

- Users may download and print one copy of any publication from the public portal for the purpose of private study or research.

- You may not further distribute the material or use it for any profit-making activity or commercial gain

- You may freely distribute the URL identifying the publication in the public portal

If you believe that this document breaches copyright please contact us providing details, and we will remove access to the work immediately and investigate your claim 


\title{
Loss models for long Josephson junctions
}

\author{
O. H. Olsen \\ Systems Engineering Department, NIRO Atomizer,Gladsaxevej, DK-2860 Soeborg, Denmark
}

M. R. Samuelsen

Physics Laboratory I, The Technical University of Denmark, DK-2800 Lyngby, Denmark

(Received 29 August 1983)

\begin{abstract}
A general model for loss mechanisms in long Josephson junctions is presented. An expression for the zero-field step is found for a junction of overlap type by means of a perturbation method. Comparison between analytic solution and perturbation result shows good agreement.
\end{abstract}

Fluxon dynamics in long Josephson junctions have mainly been investigated theoretically by means of analytical methods, ${ }^{1,2}$ perturbation analysis, ${ }^{3-5}$ and numerical simulations; ${ }^{6-8}$ only recently experiments ${ }^{9,10}$ have been performed which, however, agree almost perfectly with the theory. In Ref. 10 results from the perturbation theory for fluxon motion in the modified sine-Gordon equation are compared with experiments on long Josephson junctions of small damping constants. This comparison leads to a determination of the damping constant at various temperatures. Especially for low temperatures the experiments show that the model possibly should include the effect of surface impedance. The authors, however, note that other corrections could replace or supplement this term such as nonlinearities in the shunt conductance or inclusion of a $\cos \phi$ damping. The purpose of the present Brief Report is to present a model which takes into account nonlinearities in the shunt conductance, the $\cos \phi$ conduction, and the surface impedance. For this model we perform a perturbation analysis to obtain an expression for the stationary velocity of the fluxon and compare this result with an exact solution which can be obtained in a special case.

This equation describing fluxon $(2 \pi$-kink $)$ in long Josephson junctions is assumed to be the perturbed sineGordon equation

$$
\phi_{x x}-\phi_{t t}=\sin \phi+\eta+\sum_{i} \alpha_{i} \phi_{t}\left|\phi_{t}\right|^{i-1}(1+\epsilon \cos \phi)-\beta \phi_{x x t}
$$

with appropriate boundary conditions. We refer to Ref. 7 for a detailed description of the model. Here we only discuss the damping mechanisms. The third term on the right side represents the current through the shunt conductance (due to quasiparticle tunneling current) being a nonlinear function of voltage as proposed in Ref. 12 for the small junction. For $i=1, \quad \alpha_{1}=\left(1 / \beta_{c}\right)^{1 / 2}$, where $\beta_{c}$ is the McCumber parameter. The parameter represents the conductance due to quasiparticle interference current-physical reality requires $|\epsilon| \leqslant 1$. The last term on the right side represents surface impedance damping while $\eta$ represents the uniformly distributed bias current. We note that this model represents the pure overlap junction where the boundary conditions are $\phi_{x}(0, t)=\phi_{x}(l, t)=0$ because no selffields are present at the junction ends. For the in-line junction the antisymmetrical bias current distribution results in $\eta=0$ and self-fields give rise to boundary conditions $\phi_{x}(0, t)=-\phi_{x}(l, t)=H$ which provide energy input.

In the following we use the definition of the momentum to derive the approximate stationary velocity of the fluxon. This velocity corresponds to the voltage of the first zerofield step. The normalized momentum is defined by

$$
P=-\frac{1}{8} \int \phi_{x} \phi_{t} d x \text {. }
$$

Differentiation of $P$ with respect to time and use of (1) yields

$$
\begin{aligned}
\frac{d P}{d t}= & -\frac{1}{8}\left(\frac{1}{2} \phi_{t}^{2}+\frac{1}{2} \phi_{x}^{2}+\cos \phi-\eta \phi\right)_{x=-\infty}^{x=\infty} \\
& -\frac{1}{8} \int \phi_{x}\left(\sum_{i} \alpha_{i} \phi_{t}\left|\phi_{t}\right|^{i-1}(1+\epsilon \cos \phi)-\beta \phi_{x x t}\right) d x .
\end{aligned}
$$

Now, assuming $\phi$ is given by ${ }^{11} \phi=-\sin ^{-1} \eta+\phi^{k}(x, t)$, where $\phi^{k}$ is the $2 \pi$-kink solution to the pure sine-Gordon equation, we get

$$
P=P_{k}=u_{\infty} \gamma\left(u_{\infty}\right)
$$

and

$$
\phi_{t}=\phi_{t}^{k}=2 P \sin \left(\frac{1}{2} \phi^{k}\right),
$$

where $\gamma\left(u_{\infty}\right)$ is the Lorentz factor and $u_{\infty}$ is the stationary

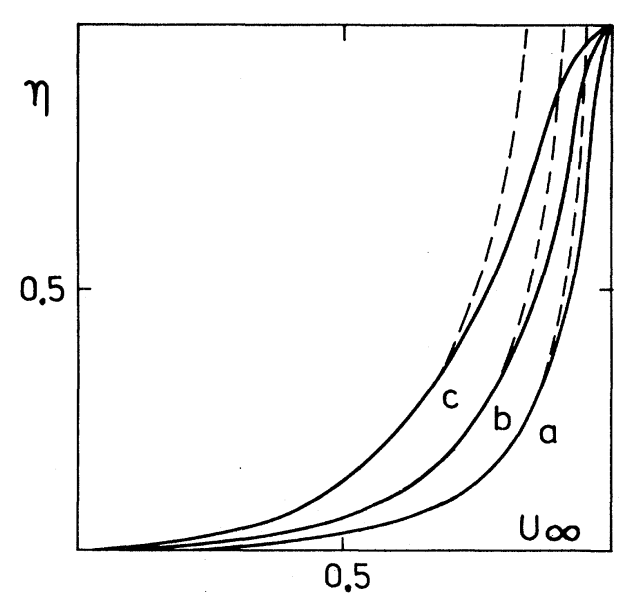

FIG. 1. Comparison between expression obtained by perturbation method and exact solution to Eq. (1). Parameter values $i=2$, $\alpha_{1}=0, \epsilon=0$, and $\beta=0$, and $\alpha_{2}=0.05$ (curve a), 0.1 (curve b), and 0.2 (curve c). Full curves represent the exact solution, dashed curves represent the result from the perturbation method. Good agreement is observed for $\eta \leq 0.4$. 
velocity. Insertion of (4) into (3) gives

$$
\begin{aligned}
\frac{d P_{k}}{d t}= & \frac{\pi}{4} \eta-P_{k}\left[\alpha_{1}\left(1-\frac{\epsilon}{3}\left(1-\eta^{2}\right)^{1 / 2}\right]-\frac{\beta}{3}\right]-P_{k}^{2} \alpha_{2} \frac{\pi}{2}\left(1-\frac{\epsilon}{2}\left(1-\eta^{2}\right)^{1 / 2}\right) \\
& -P_{k}^{3}\left[\alpha_{3} \frac{8}{3}\left(1-\frac{3}{5} \epsilon\left(1-\eta^{2}\right)^{1 / 2}\right]-\frac{\beta}{3}\right]-\frac{1}{2} \sum \alpha_{i}\left(2 P_{k}\right)^{i}\left[C_{i}\left(1+\epsilon\left(1-\eta^{2}\right)^{1 / 2}\right)-2 \epsilon\left(1-\eta^{2}\right)^{1 / 2} C_{i+2}\right],
\end{aligned}
$$

where

$$
C_{i}=\left\{\begin{array}{l}
\frac{\pi}{2} \frac{i !}{2^{i}\left[\left(\frac{1}{2} i\right) !\right]^{2}}, \quad i \text { even }, \\
\frac{2^{i-1}\left\{\left[\frac{1}{2}(i-1)\right] !\right\}^{2}}{i !}, \quad i \text { odd } .
\end{array}\right.
$$

For the stationary fluxon we have $d P_{k} / d t=0$. Thus Eq. (5) is an expression for the $I V$ characteristics of the first zerofield step. From (5) it is seen that a term $\alpha_{3} \phi_{t}{ }^{3}$ influences the zero-field step in the same way as a $-\beta \phi_{x x t}$ term. Further, we remark that the $\cos \phi$ term introduces the term $\left(1-\eta^{2}\right)^{1 / 2}$ in (5).

In order to check the perturbation method we compare the result with an exact solution. For $i=2, \alpha_{1}=0, \epsilon=0$, and $\beta=0$ the $2 \pi$-kink solution to Eq. (1) is given in Ref. 2. With use of this solution the $I V$ characteristic can be written

$$
\eta=\frac{2 \alpha_{2} P_{k}^{2}}{\left(1+4 \alpha_{2}^{2} P_{k}^{4}\right)^{1 / 2}}
$$

while Eq. (5) gives

$$
\eta=2 \alpha_{2} P_{k}^{2} \text {. }
$$

In Fig. 1 we compare the two expressions. Good agreement is observed for $\eta \leqslant 0.4$.

Finally, we remark that the influence of plasma waves on the $2 \pi$-kink motion is beyond the scope of this Brief Report but has been examined to some extent for $i=1$ in Ref. 11 .
${ }^{1}$ G. Costabile, R. D. Parmentier, B. Savo, D. W. McLaughlin, and A. C. Scott, Appl. Phys. Lett. 32, 587 (1978).

${ }^{2}$ R. D. Parmentier, in Solitons in Action, edited by K. Lonngren and A. C. Scott (Academic, New York, 1978).

${ }^{3}$ D. W. McLaughlin and A. C. Scott, Phys. Rev. A $\underline{18}, 1652$ (1978).

${ }^{4}$ O. A. Levring, N. F. Pedersen, and M. R. Samuelson, J. Appl. Phys. 54, 987 (1983).

${ }^{5}$ M. B. Fogel, S. E. Trullinger, A. R. Bishop, and J. A. Krumhansl, Phys. Rev. Lett. 36, 1411 (1976); 37, 314 (1976); Phys. Rev. B 15,1578 (1977).

6P. S. Lomdahl, O. H. Soerensen, and P. L. Christiansen, Phys.
Rev. B 25, 5737 (1982).

${ }^{7}$ P. S. Lomdahl, Technical University of Denmark DCAMM Report No. 520, 1982 (unpublished).

${ }^{8}$ S. N. Erné and R. D. Parmentier, J. Appl. Phys. $\underline{51}, 5025$ (1980); 52, 1608 (1981).

${ }^{9}$ E. Joergensen, V. P. Koshelets, R. Monaco, J. Mygind, M. R. Samuelsen, and M. Salerno, Phys. Rev. Lett. 49, 1093 (1982).

${ }^{10} \mathrm{~N}$. F. Pedersen and D. Welner (unpublished).

${ }^{11}$ O. H. Olsen and M. R. Samuelsen, Phys. Rev. B $\underline{28}, 210$ (1983).

${ }^{12}$ W. C. Stewart, J. Appl. Phys. $\underline{45}, 452$ (1974). 